\title{
Panayiotopoulos syndrome and continuous spike-wave during slow sleep
}

\author{
Síndrome de Panayiotopoulos y punta-onda continua durante el sueño lento
}

Antonio Díaz-Negrillo

A 6-year-old girl suddenly developed a loss of conciousness episode with head deviation to the left, generalized hypertonia, and clonic movements when waking up. Then, she presented vomit and bladder sphincter incontinence. Therefore, the Panayiotopoulos syndrome was suspected. Brain magnetic resonance imaging (MRI) was normal. The electroencephalography (EEG) performed after 48 hours of the episode revealed spike-wave paroxysms in parieto-occipital regions of the left hemisphere (Fig 1). During nonrapid eye movement (NREM) sleep, the EEG showed epileptiform activity of continuous spike-wave greater than $85 \%$ (Fig 2).

The Panayiotopoulos syndrome can occur in very rare cases with atypical clinical and EEG findings, being the latter central in determining the patient's prognosis ${ }^{1}$.

\section{References}

1. Caraballo R, Astorino F, Cersósimo R, Soprano AM, Fejerman N. Atypical evolution in childhood epilepsy with occipital paroxysms. Epileptic Disord 2001;3:57-62.

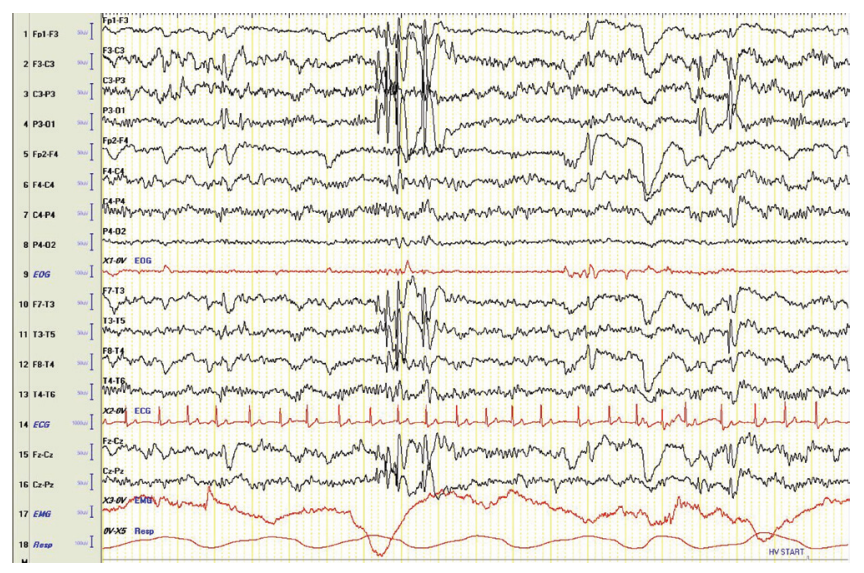

Sens: $7 \mu \mathrm{V} / \mathrm{mm}$. Time constant: 0.3 seconds. High-frequency filter: $30 \mathrm{~Hz}$. Fig 1. Waking EEG manifests the presence of some paroxysms of spike-wave in parieto-occipital areas of the left hemisphere.

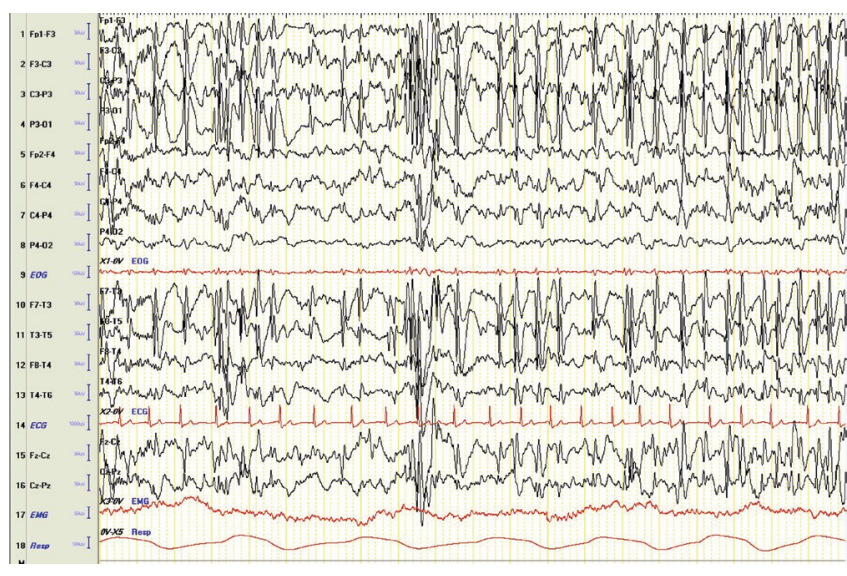

Sens: $7 \mu \mathrm{V} / \mathrm{mm}$. Time constant: 0.3 second. High-frequency filter: $30 \mathrm{~Hz}$. Fig 2. NREM sleep EEG. Epileptiform activity in the left hemisphere: continuous spike-wave greater than $85 \%$. 